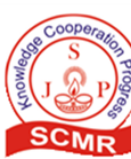

\title{
Determination of characteristic Parameters of masonry Structures via Operational Modal Analysis
}

\author{
Ali Koçak*, Burak Toydemir", Melih Bulgur\$, \\ *Department of Civil Engineering, Yildiz Technical University, Istanbul, Turkey \\ \#Istanbul Gelisim Vocational School, Istanbul Gelisim University, Istanbul, Turkey \\ ${ }^{\$}$ MPI Engineering Project Construction Contracting Industry and Trade Ltd., Istanbul, Turkey
}

(Received 10 August 2019, accepted 12 October 2019)

https://doi.org10.36224/ijes.120304

\begin{abstract}
Commonly, material and vibration characteristics of masonry structures remain uncertain in the evaluation of existing structures under external loads such as earthquake, heat, wind, etc. In addition, determination of compressive and tensile strength of a masonry walls is not straightforward. However, it is very important to know the characteristic parameters such as eigen values, periods and mode shapes of a structure beforehand in order to create accurate and reliable physical models. Since each historical structure has its own unique wall and bearing characteristics, it is not possible to accept random initial values for the bearing capacity and other parameters of the structure. Besides, conducting vertical and lateral loading experiments is costly and time consuming. An alternative way to determine these parameters that govern the structural behavior is to carry out experimental vibration tests using accelerometers. This method, which is also called as Operational Modal Analysis (OMA), is used to obtain the free and forced vibration response of structures by experimental means and to determine the modal parameters of the structure. OMA is very important for the appropriate use of an analysis method and the model parameters used in the analysis. In this study, two masonry buildings, one of which is historical, are discussed and the modal parameters of buildings are determined experimentally with OMA. Characteristic values obtained from OMA were compared with the three dimensional finite element method by adjusting characteristic model parameters.
\end{abstract}

Keyword: Masonry buildings, Operational modal analysis, Ambient vibration test, Finite element models

\section{Introduction}

Nowadays, advanced computer programs are used in the design and analysis of structures and the application projects are developed using the data provided by these programs. These programs also provide a way to carry out long and cumbersome numerical response analysis in a relatively short time. As a result of accelerated structural analysis routines, comprehensive examinations under various loading conditions can be carried out on the structures. However, various model parameters such as material properties used in the numerical modeling should well match with the ones belonging to the real-life structure. If the geometric and material parameters of real-life structure are not compatible with the adopted numerical model parameters, the comprehensive numerical analysis results are of no importance.

During dynamic analysis, the natural mode shapes of the structure are of great importance for the accuracy of the analysis. The modal parameters calculated from the model and the experimental ones must overlap. Thanks to the developing technology, the modal parameters obtained from the ambient vibration tests can be examined by comparing the numerical ones. By doing so, one can avoid from erroneous assessments of existing buildings. 
Recently, enhancements of numerical models of masonry structures by using data from experimental vibration tests has been the subject of many researchers. In the current literature, many studies related to damage detection, floor settlements, strengthening effects, and explosion or shaking effects on civil engineering structures such as reinforced concrete, steel and masonry buildings are presented. Some of these studies are related to assessment of historical masonry buildings using numerical models supported by experimental data.

Bayraktar et al. [1] studied the finite element model, modal tests and finite element calibration of a minaret located in Trabzon/Turkey. Modal parameters were obtained analytically with finite element model. Ambient vibration tests were applied under environmental impacts, wind and traffic loads. The modal parameters are defined by the selection of peaks in the frequency environment and by the stochastic sunspace identification in time domain. Experimental modal parameters such as frequency and damping ratio were compared with analytical model. Differences in the comparison results were eliminated by calibrating the model parameters that are not uncertain, such as material properties and boundary conditions in the analytical model. Following the model calibration, a very good agreement was achieved between experimental and numerical results. Aras et al. [2] used numerical and experimental methods for the structural analysis of a historical palace. Data obtained by ambient vibration tests were used to improve the numerical finite element model. In this study, the elasticity modulus, which is one of the most difficult parameters to be known, was adjusted according to the experimental data and the dynamic features of the historical palace were investigated. Koçak and Köksal [3] obtained the existing damage conditions of Küçük Ayasofya Church using the numerical finite element model calibrated by vibration measurements. In this study, data for strengthening and restoration studies are presented in the light of the earthquake effect and carrying capacity results obtained by applying linear and nonlinear analysis. Koçak and Köksal [4] analyzed the behavior of the same church under vertical and horizontal loads.

Ramos et al. [5] applied operational modal analysis using vibration, heat and humidity sensors, to two historical masonry structures. In this study, dynamic parameters are defined and the damage that may occur in historical buildings is defined in advance. Atamturktur et al. [6] investigated the uncertainty and assumptions in the numerical model by the help of experimental vibration measurements. In the study, it is aimed to obtain results closer to experimental ones.

Cagnan [7] conducted the material tests and the mechanical properties of the construction material of St. Nicholas Cathedral, were determined and the 3D finite element model was created. The numerical model was calibrated by the vibration recordings collected and the Seismic performance of the Cathedral was examined. Lacanna et al. [8] applied ambient vibration tests to obtain dynamic parameters of a historical building. Lucian Soveja [9] used OMA data in numerical analysis of a historic bell tower. In this study, the finite element model is calibrated with the use of the experimental modal parameters in order to determine the current damage and the safety level of the tower. As a result of the analysis, suggestions for strengthening were indicated. Advantages and disadvantages of different modeling techniques, finite element calibration and its applicability to historical masonry buildings are presented.

Russo [10] used pedestrian traffic, wind and a wave of the Grande Canal to dynamically assess a pile bridge using vibration measurements. Atamturktur et al.[11] used ambient vibration tests in the study of settlement damage in the buttresses of a historic church. In this study, the damaged and undamaged domes, which represent the two boundaries, were discussed, the modal parameters were identified and the 
church was examined. Ceroni et al. studied the soil-structure interaction and the effect of on a historical palace. In this study, a numerical model which idealizes the soilstructure interaction was created and calibrated by the results of operational modal analysis. The dynamic behavior of the structure has been demonstrated by comparing the finite element analysis and the experimental results. Ceroni et. al. [12]also examined the safety level of a historical building by applying nonlinear static analysis according to the Eurocode 8 regulation with operational modal analysis and finite element model.

In addition, Sevim et al., Aras et al., Osmanciklı et al., Toydemir et al. compared the parameters obtained as a result of the ambient vibration tests and the parameters obtained by the numerical model. [14 - 17].

\section{Experimental and operational modal analysis}

Experimental modal analysis and operational modal analysis are experimental methods used to determine the dynamic characteristics of structures. The advancement of technology has allowed very low amplitudes in structures to be measured with very precise accelerometers, and in this way experimental methods have been developed. These experimental methods are applied by collecting the responses of the structure resulting from the ambient vibrations and determining the structure dynamic parameters by various methods. There are many reasons for the need for experimental methods. The boundary conditions and material assumptions made in numerical modal analysis remain imprecise in determining the current dynamic characteristics of the structure. Especially the data deficiencies related to material and boundary conditions encountered in historical and masonry buildings and together with geometrical acceptances made it difficult to create accurate models. At this point, it is important to examine the feasibility of the numerical modal parameters obtained from the numerical models created in accordance with the accepted assumptions. Apart from this, it is known that the damage caused by the vertical and horizontal effects that the structures are exposed to changes the dynamic behavior of the structure or the factors resulting from the construction phase of the structure may lead to change in the dynamic characteristics. As the experimental measurement methods allow obtaining the experimental dynamic characteristics of the structure, the differences caused by the uncertainties can be diminished. With the realistic data reached, the previously developed theoretical models can be improved and closer analysis can be made with the finite element models in which the structural behavior can be analyzed in a more realistic way.

The measurements on the structures can be separated into two class, the Forced Vibration Testing (FVT) and the Ambient Vibration Testing (AVT). During the forced vibration test, as the name suggests, an external force is applied to the structure to make measurements. The most important advantage is that the measurements are performed against a predetermined and controlled force. In some rare cases, it can be used in uncontrolled forces such as explosives and vehicles.

In the experimental modal analysis method, the vibration force used in the measurements is known and the response received is due to a known vibration force effect. In this method, a force is applied to the structure and the acceleration of the structure is measured in response. The impact force applied to the structure is created using shakers, impact hammers etc. Experimental modal analysis may be summarized as shown in Figure 1. First, accelerometers are placed in certain parts of the structure. The structure is then vibrated to collect the data. Then, FRF (Frequency Response 
Function) analysis can be performed, such as Peak-Picking, PP, Least Square Complex Exponential Fit, Frequency Domain Polynomial Fit, and FRF Synthesis. Modal parameters are obtained using various algorithms [18].

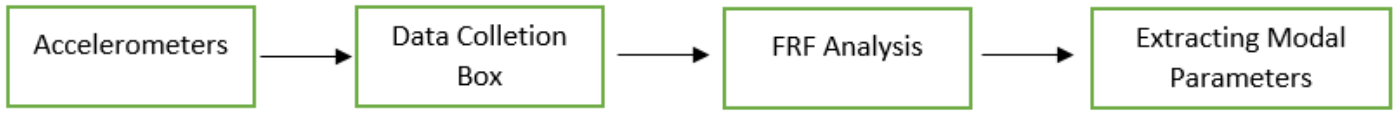

Figure 1: Experimental modal analysis

In the operational modal analysis method, the vibrational records are collected and the modal parameters are obtained by collecting the accelerometers. However, in this method, the reactions of the structure under environmental effects such as wind, vehicle and live activities are collected without applying a force to the structure. This method, in which only structural responses are used, is a more recent method than experimental modal analysis, and it is one of the advantages of the method that does not require interruption of the activities in the structure, lower cost of equipment and not damage the structure with the vibrators used. Operational modal analysis is performed as shown in Figure 2.

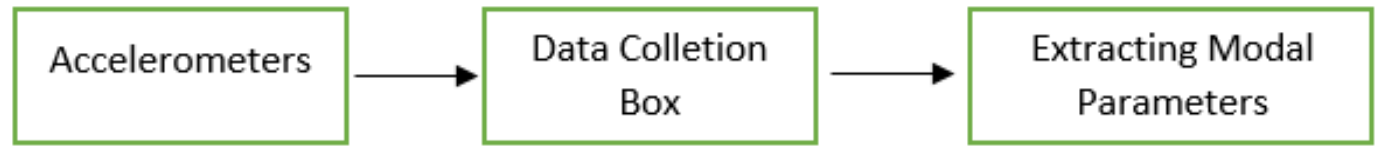

Figure 2: Operational modal analysis

Since the environmental effects are not fully known in the operational modal analysis, different algorithms are used in the extraction of the modal parameters from the vibration measurements [21] The most commonly used methods are Frequency Domain Decomposition, FDD and Stochastic Subspace Identification (SSI). In this study, the uniaxial and biaxial Sensebox 7000 series accelerometers are used during the measurements.

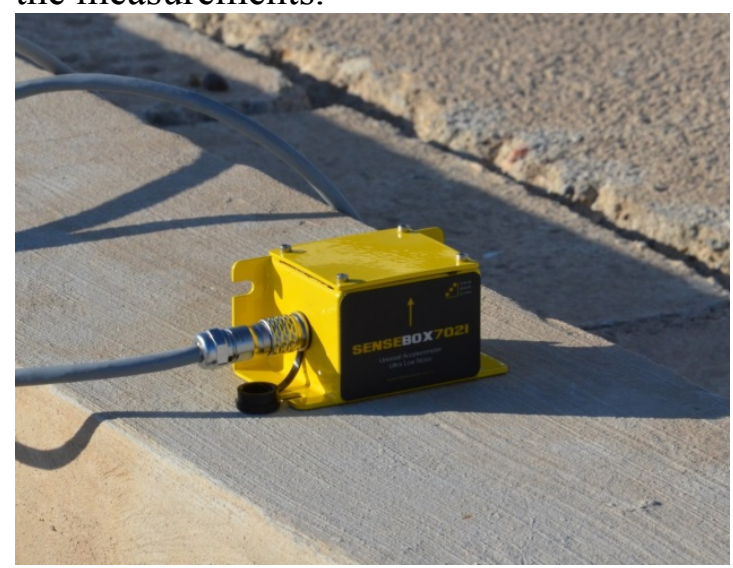

Figure 3: SenseBox 7021 accelerometer

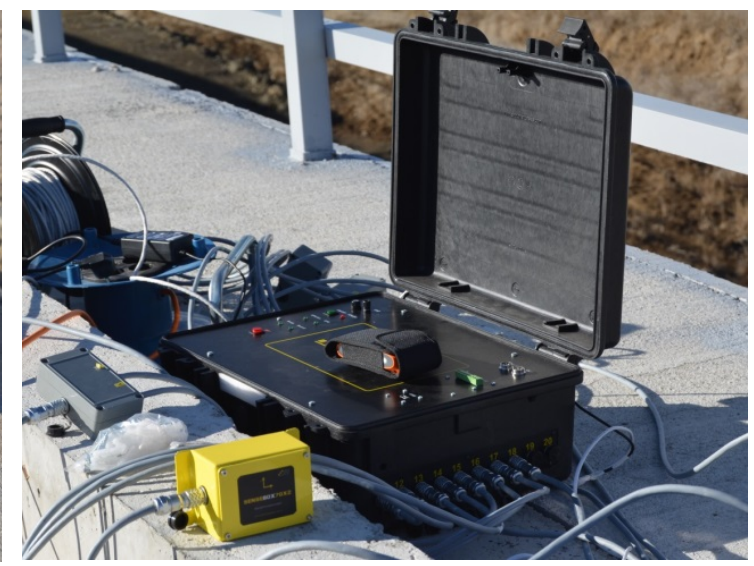

Figure 4: TestBox 2010 data acquisition

As we do not need to calculate all natural frequencies of the structure during the control of the accuracy of the modal calculations obtained from the numerical model, a first few modes are sufficient to extract. Considering the dynamic properties of structures that are investigated in this study, it is convenient to eliminate the frequency content that are below $0.5 \mathrm{~Hz}$ and above $15 \mathrm{~Hz}$. Hence, Butterworth Bandpass Filter has been applied. In order to avoid loss of valuable content of signals, 
the filter level was tried to be kept as low as possible without disturbing the filter stability.

Filtered signals are analyzed by Artemis Modal Analysis Package program [19], which is produced by Structural Vibration Solutions, by the Operational. FDD (Frequency Domain Decomposition) technique was used during the analysis. In the FDD technique, the modal parameters of the structure are determined under the influence of Gaussian White Noise. In the Artemis Modal program, signals are collected and the coordinates of the signals are determined. Then, the program calculates the FRF (Frequency Response Function) and Spectral Density of filtered signals, and finally extracts the modal parameter values in the light of these data [18 20].

\subsection{Investigated Buildings and OMA results}

\subsubsection{Building \#1}

The first of the structures examined is HünkarKasr-i located in the Davutpaşa Campus of Yildiz Technical University. The structure was built by KocaDavut Pasha in 14821491 during the Ottoman Period in Istanbul to accommodate the Sultan before he left for the campaign. HünkarKasr-1 was on the caravan road connected to Edirne city, which was also known as 'Via Egnita'. This region, which was evaluated with military areas before the Ottoman Empire, is known as the Davutpaşa Sahara which was used for military purposes during the Ottoman period. HünkarKasr-1, which had been used for military purposes until 1999, was allocated to Yildiz Technical University in 1999 [20].

The structure is a two-storey building and also called as Otağ-1Humayun was built with a finely cut lime stone. It was then restored by Yildız Technical University. It consists of entrance hall, divanhane, service rooms and staircases. The east, north and south facades of the building are shown in Figure 5, Figure 6 and Figure 7, respectively, while the ground floor plan is shown in Figure 8.

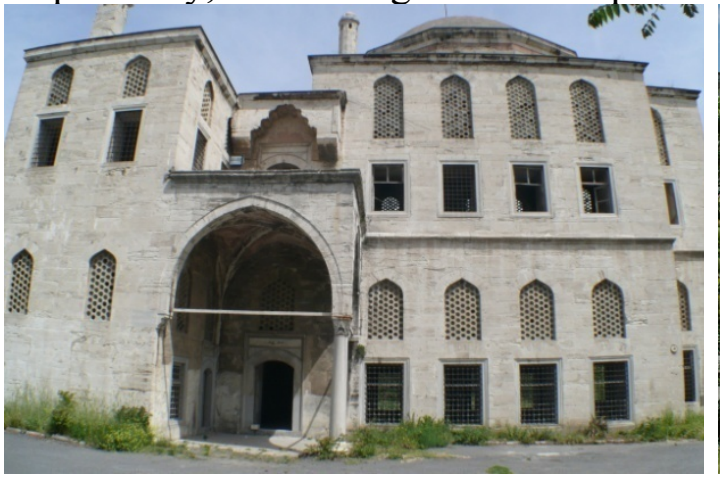

Figure 5: HünkarKasr-1 east facade

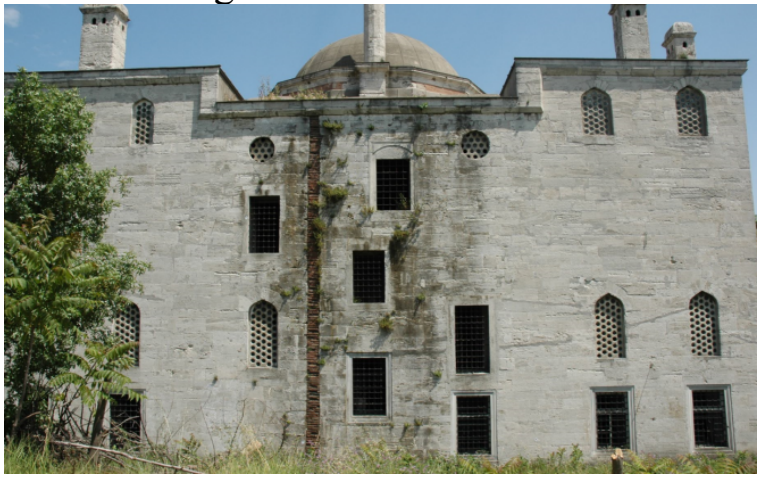

Figure 6: HünkarKasr-1 South facade 


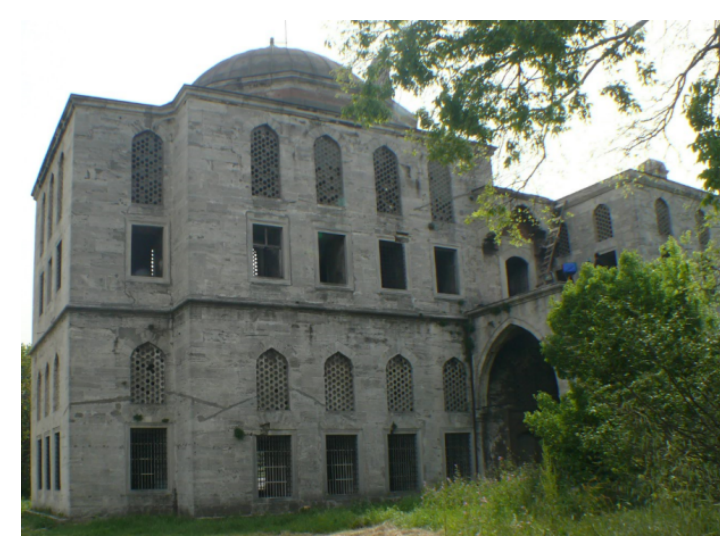

Figure 7: HünkarKasr-1North facade

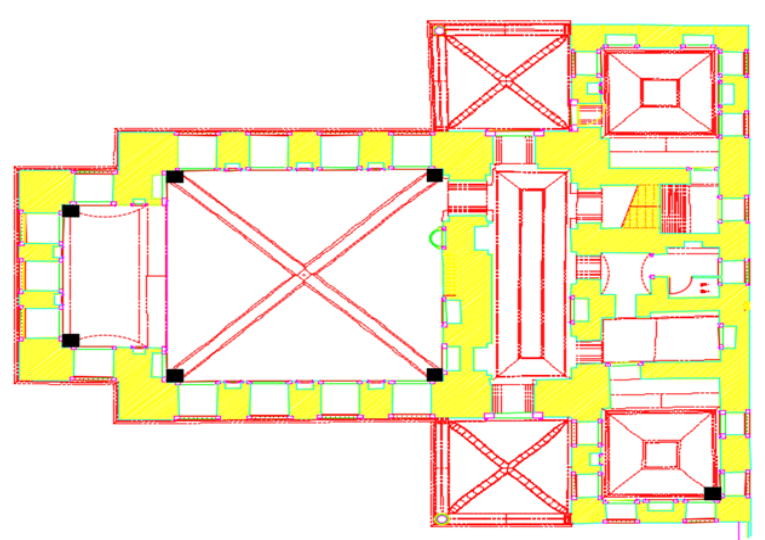

Figure 8: Plan view

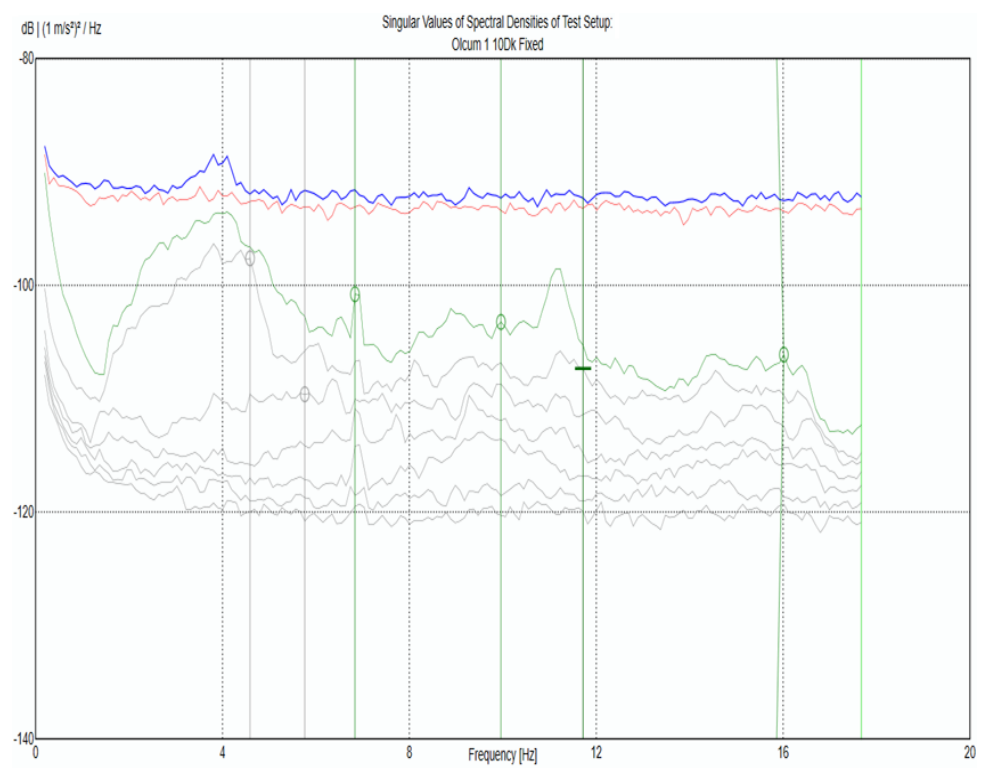

Figure 9: Extraction of modal parameters

Single-axis and dual-axis accelerometers were used for operational modal analysis. The accelerometers were placed as shown in Figure 8 and the vibration of the historic building under ambient effects was recorded. Three measurements were made for 10-15 minutes using accelerometers shown by black rectangles in Fig.8. Accelerometers are generally placed at the edges of the building and close to the upper floor. After all the accelerometers have been installed, they have been checked, inspected under environmental and forced vibration. Unregistered seismometers have been modified and the new seismometers have been checked and the registration process has begun. The signals passed through the necessary filters were converted to graphical images via the package program Artemis and the dynamic parameters were examined (Figure 9,10 and 11). 


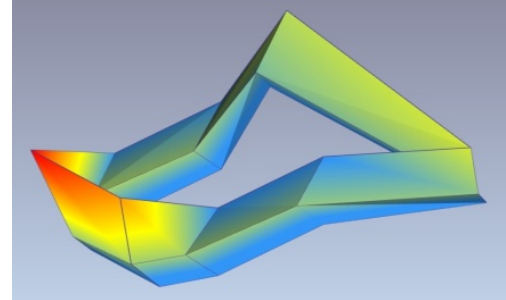

Figure 10: First

Experimental Mode Shape

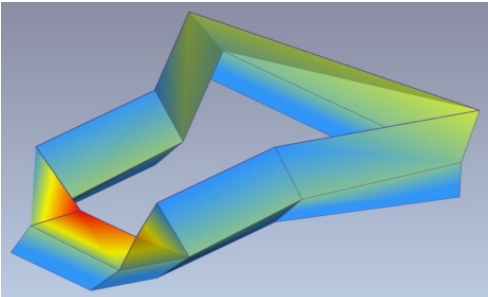

Figure 11: Second

Experimental Mode Shape

The 3D finite element model of HünkarKasr-1 was created using the software ETABS. First of all, wall thicknesses were defined and structural geometry was formed. The walls are modeled with shell elements as in Figure 12.
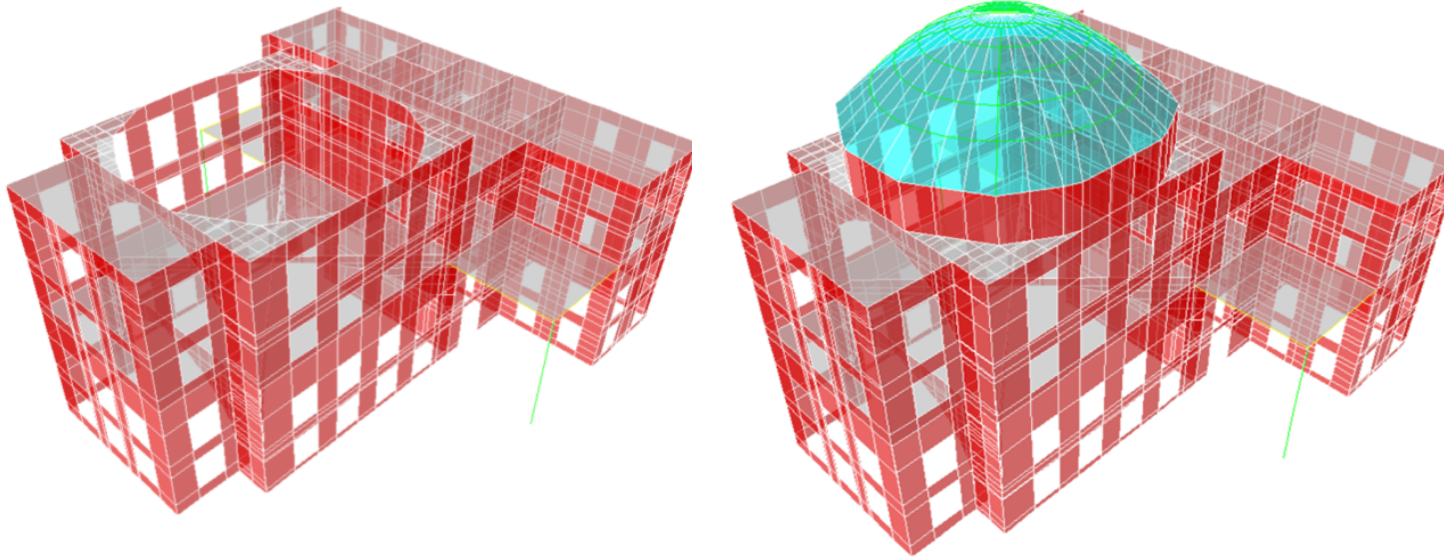

Figure 12: FE model of the Otag-1Humayun

As can be seen from Table 1, the modal frequency values obtained by the numerical model of the structure are very close to each other. The modal shape obtained from Etabs [21] model is given in Figure 13.

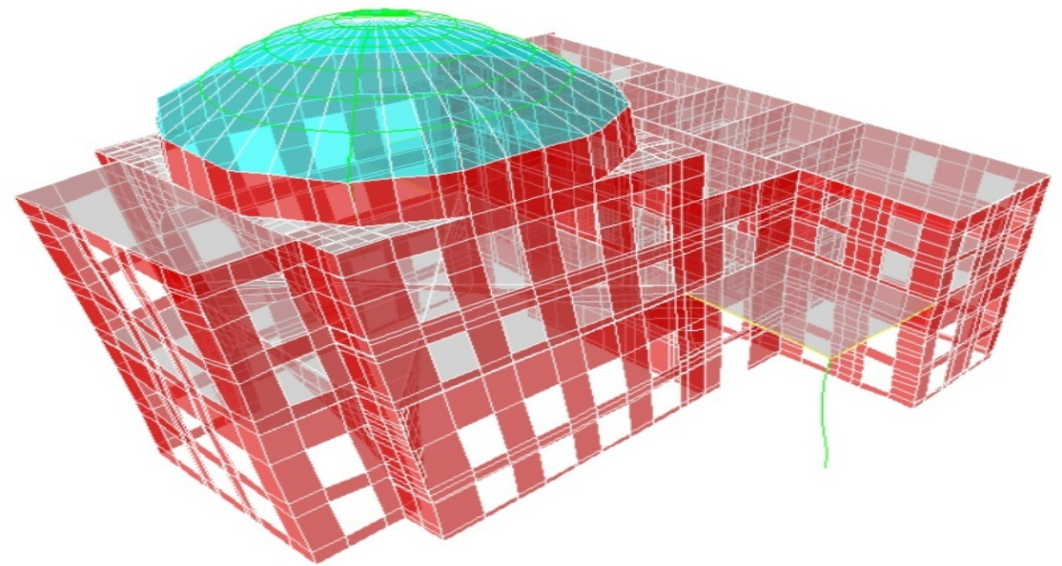

Figure 13: Fundamental mode shape $f=4.59 \mathrm{~Hz}$

Table 1: Comparison of numerical and experimental frequencies

\begin{tabular}{llll}
\hline Mod No & Artemis $(\mathbf{H z})$ & ETABS $(\mathbf{H z})$ & Damping [\%] \\
\hline $\mathbf{1}$ & 4,59 & 5,04 & $9.80 \%$ \\
\hline $\mathbf{2}$ & 5,762 & 6,15 & $6.73 \%$ \\
\hline $\mathbf{3}$ & 6,474 & 7,96 & $22.95 \%$ \\
\hline $\mathbf{4}$ & 9,948 & 9,20 & $-7.52 \%$ \\
\hline $\mathbf{5}$ & 11,719 & 10,53 & $-10.15 \%$ \\
\hline
\end{tabular}




\subsubsection{Building \#2}

The second masonry building is located in Kursehir/Turkey. This structure is shown in Fig. 14. It is a single story building with $105 \mathrm{~m}^{2}$ in plan. The accelerometer locations are given in Fig 155 Bi-directional and 2 uni-directional accelerometers have been used. The data from the accelerometers have been collected through the test box.

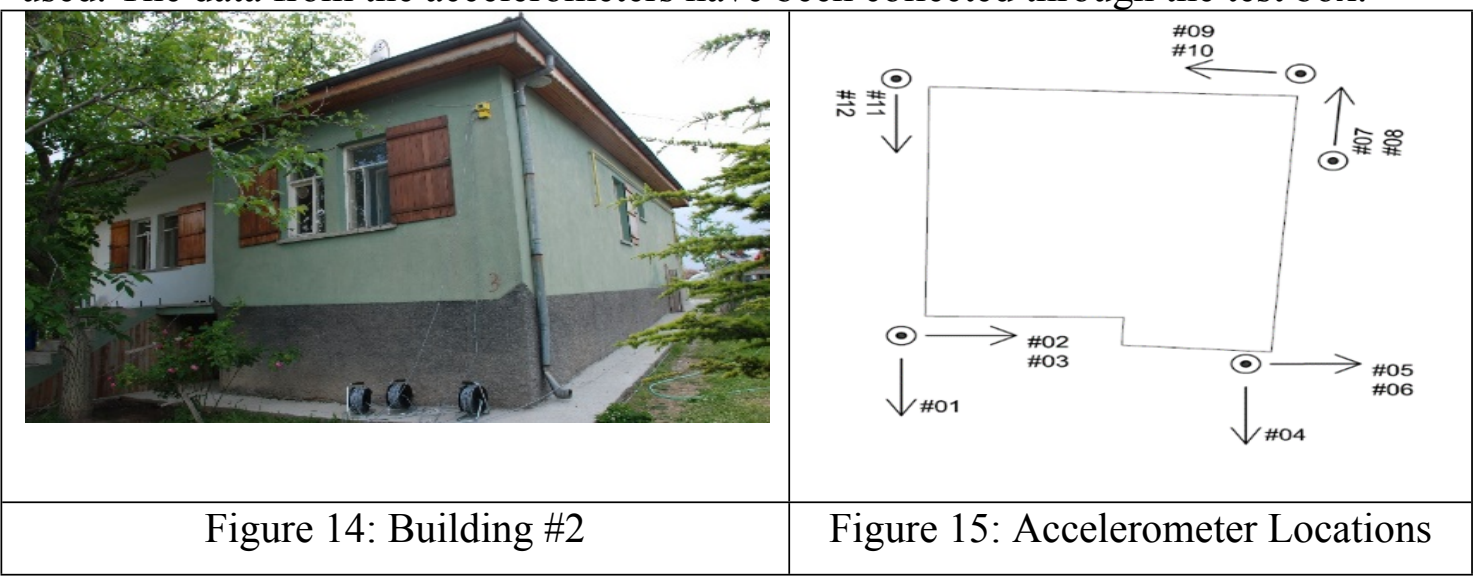

The collected data have been analyzed through Artemis software and the singular value graph for the building is in Fig 16.

$\mathrm{dB} \mid\left(1 \mathrm{~m} / \mathrm{s}^{2}\right)^{2} / \mathrm{Hz} \quad$ Singular Values of Spectral Densities of Test Setup:

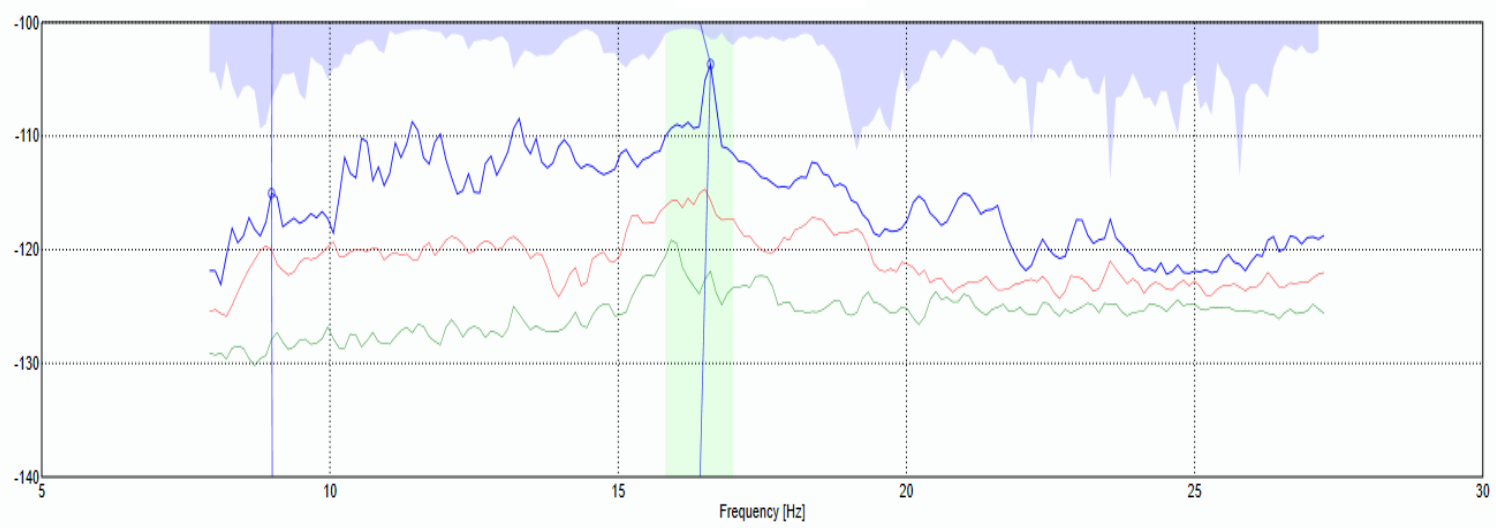

Figure 16: Singular Value Decomposition for Building \#1

Modulus of Elasticity for Building \#2 was estimated as $2700 \mathrm{Mpa}$. The estimated modal frequencies from Artemis Software and modal frequencies of 3D Model based on estimated Modulus of Elastisity is given in Table \#2.

Table 2: The estimated modal frequencies from Artemis Software and modal frequencies of 3D Model based on estimated Modulus of Elastisity

\begin{tabular}{cccccc}
\hline Mode \# & \multicolumn{2}{c}{ Artemis Results } & \multicolumn{3}{c}{ 3D Model } \\
\cline { 2 - 6 } & $\begin{array}{c}\text { Frequency } \\
{[\mathbf{H z}]}\end{array}$ & $\begin{array}{c}\text { Damping } \\
{[\%]}\end{array}$ & $\begin{array}{c}\text { Frequency } \\
{[\mathbf{H z}]}\end{array}$ & $\begin{array}{c}\mathbf{E} \\
\left(\mathbf{N} / \mathbf{m m}^{2}\right)\end{array}$ & $\begin{array}{c}\text { Poisson } \\
\text { Ratio }\end{array}$ \\
\cline { 2 - 6 } $\mathbf{1}$ & 11.268 & 2.574 & 11.676 & 2700 & 0.2 \\
\hline $\mathbf{2}$ & 13.609 & 1.814 & 13.617 & 2700 & 0.2 \\
\hline
\end{tabular}

The mode shapes extracted from finite element software are shown in Figure 17 and these are coherent with the results extracted from Artemis Software. 


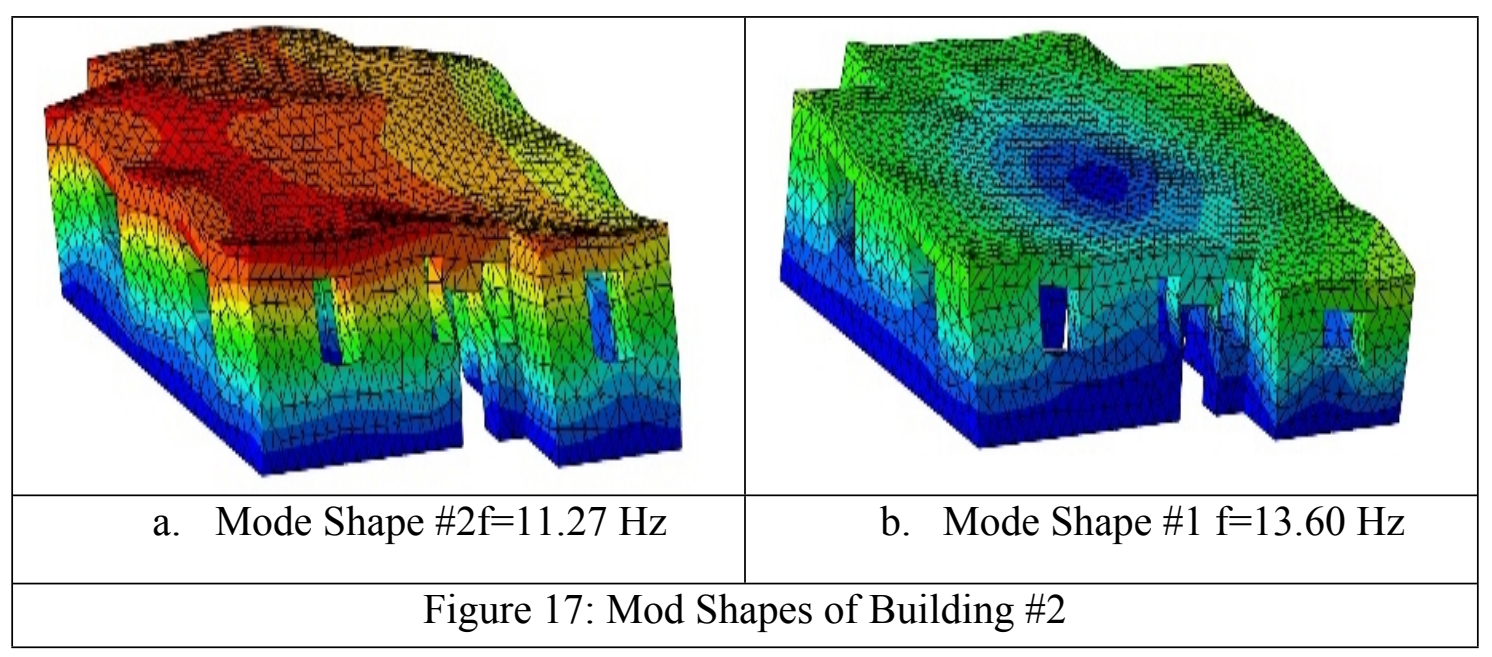

\section{Conclusions}

In this research, the dynamic characteristics of two different structures have been investigated using finite element based software and ambient vibration testing. The ETABS and ABAQUS software have been used for 3D modelling of the structures. The dynamic parameters have been obtained. The ambient vibration testing has been conducted on structures by using accelerometers that have been located based on modal shapes obtained from finite element software. The following conclusions have been made

- The mechanical parameters that have been used in finite element analysis is evaluated based on ambient vibration testing.

- First five natural frequencies from building \#1 and first two natural frequencies from Building \#2 have been obtained.

- The damping ratios have been changed between 1.8 and $2.6 \%$

- Longitudinal bending, vertical bending and torsional modes have been obtained from both finite element analysis and ambient vibration testing.

- For Building \#1, modal frequencies have been extracted in $6.73 \%$ to $22.95 \%$ convergences

- For Building \#2 modal frequencies have been extracted in $1 \%$ convergence.

As a result of little differences between experimental and analytical results, FEMs are considered as accurate models for future analysis.

\section{References}

1. Bayraktar, A., Altunişik, A.C., Sevim, B., Türker, T., Akköse, M., Çoşkun, N., Modal Analysis, Experimental Validation, and Calibration of a Historical Masonry Minare,Journal of Testing and Evaluation, 2008, 36, 6, 516-524

2. Aras, F., Krstevska, L., Altay, G., Tashkov, G., Experimental and numerical modal analyses of a historical masonry palace, Construction and Building Materials, 2011, 25, 81-91

3. Koçak, A., Köksal, T., An example for determining the cause of damage in historical buildings: Little hagiasophia (Church of St. Sergius and Bacchus) Istanbul, Turkey, Engineering Failure Analysis, 2010, 17, 926-937

4. Koçak, A. veKöksal, T., Investigation of Earthquake Behavior of the Church of St. Sergius and Bacchus in Istanbul/Turkey, Advanced Materials Research, 2010, 133-134, 821-830 
5. Ramos, L.F., Marques, L., Lourenço, P.B., De Roeck, G., Campos-Costa, A. Ve Roque, J., Monitoring historical masonry structures with operational modal analysis: Two case studies, Mechanical Systems and Signal Processing, 2010, $.24,1291-1305$

6. Atamturktur, S., Hemez, F., M., Laman, J.,A., Uncertainty quantification in model verification and validation as applied to large scale historic masonry monuments, Engineering Structures, 2012, 43, 221-234

7. Cagnan, Z., Numerical models for the seismic assessment of St. Nicholas Cathedral, Cyprus, Soil Dynamics and Earthquake Engineering, 2012, 39, 50-60.

8. Lacanna G., Ripepe, M., Marchetti, E., Coli, M. veGarzonio, C.A., Dynamic response of the Baptistery of San Giovanni in Florence, Italy, based on ambient vibration test, Journal of Cultural Heritage, 2016, 20, 632-640

9. Soveja, L., Gavriloaia, C., Structural Assessment and Proposed Intervention Works on a Historic Masonry Tower, The Bulletin of the Polytechnic Institute of Jassy, Construction. Architecture Section, 2015, 61, 1, 45-55

10. Russo, S., Integrated assessment of monumental structures through ambient vibrations and ND tests: The case of Rialto Bridge, Journal of Cultural Heritage, 2016, 19, 402-414

11. Atamturktur, S., Bornn, L., Hemez, F., Vibration characteristics of vaulted masonry monuments undergoing differential support settlement, Engineering Structures, 2011, 33, 2472-2484

12. Ceroni, F., Sica, S., Pecce, M., Garofano, A., Evaluation of the natural vibration frequencies of a historical masonry building accounting for SSI, Soil Dynamics and Earthquake Engineering, 2014, 64, 95-101

13. Ceroni, F., Pecce, M., Sica, S., Garofano, A., Assessment of Seismic Vulnerability of a Historical Masonry Building, Buildings, 2012, 2, 332-358

14. Sevim, B., Bayraktar, A., Altunişik, A.C., Atamtürktür, S. veBirinci, F.,. Finite element model calibration effects on the earthquake response of masonry arch bridges, Finite Elements in Analysis and Design, 2011, 47, 621-634

15. Aras, F., Krstevska, L., Altay, G. veTashkov, L, Experimental and numerical modal analyses of a historical masonry palace, Construction and Building Materials, 2011, 25, 81-91

16. Osmancikli, G., Uçak, Ş., Turan, F.N., Türker, T. veBayraktar, A., Investigation of restoration effects on the dynamic characteristics of the Hagia Sophia belltower by ambient vibration test, Construction and Building Materials, 29, 564572

17. Toydemir, B., Koçak, A., Sevim., B., Zengin, B., Ambient Vibration Testing and Seismic Response of Precast I Beam Bridges on A High-Speed Railway Line, Journal of Steel and Composite Structures, 2017, 23, 5, 557-570

18. Ercan, E, Determination of Masonry Structures Safety by Analytical and Experimental Methods, PhD Thesis, Ege University, Graduate Faculty of Natural and Applied Science, İzmir (in Turkish), 2010

19. Artemis Modal, V3, Structural Vibration Solutions A/S, Aalborg East Denmark, 2014

20. Çetiner, Z., Davutpasa Barracks and Its Place in the Barracks of Istanbul, Graduate Thesis, Y1ldiz Technical University, Graduate School of Science And Engineering, İstanbul. (in Turkish), 1996

21. Etabs, Version 9, Integrated building design software, computers and structures, Inc. Berkeley, California, USA, 2005 